\title{
Construction of Tourism Management Mode Based on Project Man- agement Theory
}

\author{
Hua E \\ Heilongjiang University of Technology, Jixi, Heilongjiang, China, 158100
}

Key words: tourism management; project management; construction model

Abstract: It is one of the most important factors influencing the development and improvement of the tourism management. To establish a comprehensive and perfect tourism management model is one of the most important factors in the development of the tourism industry, it is also constantly improving its own. Whether it is normal day-to-day operation or practical benefits, the need of project management theory is the main basis. Now the reality of the situation, the project management theory has gradually been used to the tourism management related to the operating mode. This paper will analyze the basic theory of project management and the impact of the basic management mode of tourism management to discuss and summarize the introduction of the project theory in the modern tourism management model to create a specific way to explore.

In the process of carrying out a certain project activity, the use of various means, including technology, skills, knowledge or tools, so that the needs of the entire activities and activities to achieve the desired objectives of the project can achieve a more appropriate level of demand. The process can be called project management. Now the reality of the situation, the project management theory has become a modern business management process which is a more important discipline, which in all areas of culture are reflected. With the deepening of reform and opening up, the mode and level of economic development have gradually realized a more comprehensive improvement, and actively use the local tourism resources for tourism economic development, has gradually become the focus of development. In the process of establishing modern tourism management model, the basic theory of project management can be used appropriately, which can bring more high overall management level to the tourism industry. This paper will start the analysis.

\section{Overview of project management theory and tourism management model}

A. On the basic theory of project management

The so-called project, refers to a particular product or a service, subject to certain conditions and restrictions, to a given goal of continuous efforts, and then use all available resources to its Technical guidance intervention, so that resources can be in the overall level, time and cost to expand the appropriate allocation of consumption, and then effectively enhance the quality of the activities of the entire project level. Under the influence of an organizational environment, project management can effectively adjust the overall progress of resources, and then make the project in the implementation process can have certain timeliness. In a specific scope, the project management 
has good effect of project control, in the process of project operation, can provide more effective management and human resources; fully mobilize the team has the leading role, so that the activities of the project staff Project management can naturally have a more significant risk, it can make more unstable activities in the risk of the project as much as possible to avoid being affected by the risk of impact. The relevant theories of project management have important practical effects on the creation of tourism management mode and the development of scenic spots. In order to reduce the risk of occurrence of risk events and cost problems in the process of tourism management, the local governments and relevant units all have The need to develop the tourism industry as soon as possible the development model to achieve all aspects of the tourism industry, all aspects of the comprehensive control, and then make the tourism management from the project management to obtain benefits.

\section{B. Management Model of Tourism Management}

On the tourism management at the grassroots level, middle and senior management process, no matter what level of management model has a certain characteristics of project management. Its management mode at the grassroots level mainly covers planning and assigning the tasks involved in each project while ensuring its effective implementation. In the middle management mode, it mainly covers the various problems arising in the activity project, Project quality level and cost, progress and other aspects of effective supervision and management, the project in the implementation process of the problems arising from appropriate treatment. However, in terms of senior management, its main cover and external relations to deal with the part, the most important is the development of tourism projects and local management units and other local government departments to cooperate and communicate. Thus, it plays the role of decision-making in the senior management process. The reality of the situation, the tourism industry for private enterprises and foreign investment projects which have become more and more, the process of tourism development and construction will also be a series of various types of contradictions, it is necessary in accordance with foreign-funded enterprises and Private enterprises in the process of project construction in all aspects of the use and composition of elements, building a more ideal management model.

\section{The basic theory of project management and the mode of tourism management}

\section{A. Strengthen project evaluation work}

In the process of tourism management, the relevant work of project evaluation is a relatively important part. During the preparation of the activity project, detailed and comprehensive analysis and investigation are needed, and then the feasibility of the project can be evaluated effectively. In the process of project evaluation by the tourism management unit, it is necessary to carry out the analysis and the corresponding actual investigation in order to make the project more feasible and necessary for its implementation and construction. In addition, documents and data needed to be 
assessed need to be entrusted to the relevant units and scholars to conduct in-depth exploration, so that not only can make the whole tourism project in the implementation process to achieve the desired results, but also the rational use of local tourism resources, So that tourism can be developed and improved as soon as possible in the cultural and economic fields. To strengthen the assessment of the project is to work on the progress of the entire project schedule and cost management, the progress of tourism projects in the process of management, sorting and scheduling for the activities of the system; the cost of tourism projects in the process of management, For the need to implement the activities involved in the scope of budget and control costs are properly managed; the quality of tourism projects in the process of management, quality assessment and quality improvement for a comprehensive assessment. In order to be able to effectively implement the tourism projects in an orderly manner, it is necessary to comprehensively analyze the daily life and production of local residents before carrying out resource development work.

B. The project management system to improve

At present, China's government departments on the tourism project in the process of comprehensive development, most of them will use foreign investment this model. There are many investment units in the process of project development are only emphasized the reality of interest, ignoring the process of construction of the scenic area may be the formation of destructive development and a large number of waste of resources phenomenon. The basic theory of project management which is related to the need to achieve a higher degree of tourism projects, as the relevant units need for the development of tourism projects need to use the appropriate monitoring mechanism, so that their activities in tourism management projects which give full play to their own Of the leading role, and thus effectively promote the sustainable development of the tourism industry measures. In most cases, the leadership of the management unit, not only need to fully control the realities of the tourism industry, but also need take into account other departments. Although in the management process, to a certain extent, to solve some of the problems encountered in the development of tourism projects, but to some extent, there may be a lot of management loopholes, so you can put the basic tourism management The model is set up as a unit which can be managed independently, so that it can play a more important decisive role in the management of the development of tourism projects and project research process, the need to ensure its development feasibility and stability.

C. The implementation of information systems and management methods

Implementation and implementation of information technology management is usually relatively large in some of the activities of tourism projects in the construction work carried out to achieve the construction of information-based tourism management, which can be properly used in the construction industry project management work used in the advanced information systems. After the use of a large extent to achieve the optimal management model, but also in the process of project 
construction for the quality level and cost levels, construction progress and other unified and comprehensive management, to achieve specific, comprehensive, comprehensive all-round Management system. The implementation of information management process, which can be integrated use of graphics, tables, data, etc., for the consolidation of the database, after the data and information on the basis of dynamic analysis. For example, the management of more scientific construction costs, then the cost of construction for some of the dynamic information to carry out an effective analysis. Combined with the implementation of the actual development of the project law, it needs to establish coordinated, flexible and systematic organization of various projects. After the use of modern multimedia technology, so that the project management to achieve a high degree of information automation.

D. Build a customer service as the main object of the project management model

Generally speaking, project management can play the overall effect of project control in a specific scope. In the process of project operation, project management can play a more ideal way of human resource coordination and project management, and make project management related Theory can be skillfully used throughout the process of tourism management, customer management is the main basis for project management. To bring more targeted customers a variety of service models is the most important purpose of tourism management. For example, we take the scenic tourism management model as an example, the customer as the main project management object, the provision of tourism services can establish a very good image of the tourist attractions, enhance customer satisfaction, based on the regional scenic spots to Better development.

If the basic theory of project management as the core content achieves the development of tourism management industry, the customer service maintenance links which can be properly integrated project management basic theory, the need for service projects to start customer segmentation. In general, different types of customers, their demand for the product there will be more significant differences. Along with today's growing socio-economic level, the creation of eco-tourism products based on the need to combine the user's travel routes needed to make appropriate adjustments.

Therefore, we can think that, in the actual development of tourism resources which link the project management theory related to the use of tourism management which effectively expand the service market for tourism services to attract more customers. After the customer resources have accumulated to a certain scale, they can carry out a comprehensive user survey, summarize the characteristics of the tourism customers and make a scientific and reasonable distinction, and formulate a targeted eco-tourism marketing program. As a basis, to provide customers with a specific targeted to improve services. In addition, the use of complementary product lines to meet customer needs, for example, for some in the vicinity of tourist attractions operating hotels or hotels, to monitor its overall quality of service and level, to create a good environment for customers. 


\section{Conclusion:}

On the reality of China's situation, the rapid development of tourism management model has been reflected in the governance of the more distinctive administrative colors, so its comprehensive innovation has gradually become a very critical content. In order to be able to carry out tourism management in the process of achieving a higher level of scientific nature, through scientific theory to carry out in-depth guidance, in this paper, the study of the impact of project management, tourism management, supervision. Development and other aspects of the formation of mutual restraint, then make tourism management industry to achieve a more high degree of sustainable development.

\section{Reference}

[1] as a bright and beautiful, xiao-yan Chen. Tourism type teaching model research project management [J]. Journal of teaching research, 2013 (03)

Lu Shuang. [2] of the tourism management mode based on the theory of project management to create [J]. J, 2013 (11)

[3] Qiao Yujing. Based on the theory of project management, event tourism management analysis [J]. Journal of shenyang institute of education, 2011 (01)

[4] zhou li. Based on the practice of tourism management professional training project applied talents training mode innovation exploration [J]. Journal of nanjing xiaozhuang college, 2015 (6)

[5] Yu Yiming. Create tourism safety management system and safety education interactive model [J]. Journal of wuhan vocational and technical college, 2012 (03) 